\title{
Influence of Glycomacropeptide on Rehydration Characteristics of Micellar Casein Concentrate Powder
}

\author{
Ram R. Panthi, Francesca Bot and James A. O'Mahony *
}

check for updates

Citation: Panthi, R.R.; Bot, F.; O'Mahony, J.A. Influence of Glycomacropeptide on Rehydration Characteristics of Micellar Casein Concentrate Powder. Foods 2021, 10, 1960. https://doi.org/10.3390/ foods10081960

Academic Editor: Isidra Recio

Received: 6 August 2021

Accepted: 19 August 2021

Published: 23 August 2021

Publisher's Note: MDPI stays neutral with regard to jurisdictional claims in published maps and institutional affiliations.

Copyright: (C) 2021 by the authors Licensee MDPI, Basel, Switzerland. This article is an open access article distributed under the terms and conditions of the Creative Commons Attribution (CC BY) license (https:/ / creativecommons.org/licenses/by/ $4.0 /)$.
School of Food and Nutritional Sciences, University College Cork, T12TP07 Cork, Ireland; ram.panthi@ucc.ie (R.R.P.); francesca.bot@ucc.ie (F.B.)

* Correspondence: sa.omahony@ucc.ie; Tel.: +353-21-4903625

\begin{abstract}
Glycomacropeptide (GMP) shows potential for enhancing the rehydration properties of high-protein dairy powders due to its hydrophilic nature. This study involved formulating micellar casein concentrate (MCC) solutions (8.6\% final protein content) with 0,10 , and $20 \%$ GMP as a percentage of total protein, and investigated the physicochemical and rehydration properties of the resultant freeze-dried powders (P-MCC-0G, P-MCC-10G, and P-MCC-20G, respectively). The surface charges of caseins in the control MCC and 10 or $20 \%$ GMP blended solutions were $-25.8,-29.6$, and $-31.5 \mathrm{mV}$, respectively. Tablets prepared from P-MCC-10G or P-MCC-20G powders displayed enhanced wettability with contact angle values of $80.6^{\circ}$ and $79.5^{\circ}$, respectively, compared with $85.5^{\circ}$ for P-MCC-0G. Moreover, blending of GMP with MCC resulted in faster disintegration of powder particles during rehydration (i.e., dispersibility) compared to P-MCC-0G. Faster and more extensive release of caseins from powder particles into solution was evident with the increasing proportion of GMP, with the majority of GMP released within the first $15 \mathrm{~min}$ of rehydration. The results of this study will contribute to further development of formulation science for achieving enhanced solubility characteristics of high-protein dairy powder ingredients, such as MCC.
\end{abstract}

Keywords: glycomacropeptide; micellar casein concentrate; powder rehydration

\section{Introduction}

High-protein, casein-dominant powders (e.g., micellar casein concentrate, milk protein isolate, milk protein concentrate) are newer-generation ingredients with significant market potential because of their techno-functional properties such as emulsification and gelation, as well as nutritional attributes [1,2]. However, such powders generally display poor rehydration properties when dissolved in aqueous media, which limits their application as demanded by end-users and consumers [3]. Developing an understanding of advanced mechanisms during the rehydration of casein-dominant powders has been the focus of many recent studies [2,3]. Mechanistically, primary powder particles disintegrate into smaller particles, subsequently releasing caseins into solution [4]. However, prior to a complete disappearance of primary powder particles, wetting, sinking, swelling, and dispersion occur, and casein-dominant powders typically show longer dispersion times compared with conventional milk powders, such as skim milk powder [3]. Powder particles with poor rehydration characteristics interact slowly with water [5,6], which is likely influenced by the closely fused casein micelles at the powder surface [7], leading to the development of hydrophobic surface properties [8].

Recent research has shown the importance of the physicochemical properties of feed material in enhancing rehydration properties of resulting high-protein dairy powders [2]. On concentration of milk systems, the distance between casein micelles reduces considerably, and caseins are more likely to interact and fuse with nearby casein micelles [9]. The fusion of such casein material results in poor dispersibility of subsequent powders [7,10]. Therefore, formulation strategies that restrict micellar interactions show promise in enhancing rehydration properties of casein-dominant powders [11,12]. For example, micellar 
casein solution mixed with up to $12 \%$ sodium caseinate [12] or sodium chloride, whey proteins, citrate, or phosphate [6] showed improvement in rehydration characteristics of subsequent powders. Milk protein concentrate (MPC) dispersion mixed with nano-sized spacers containing lipid (lecithin, up to $10 \%$ of total solids) before spray drying showed enhanced solubility characteristics of resultant powder when the powders were stored for an extended period [11]. Sun et al. [13] added 0.3\% salts (sodium citrate, sodium pyrophosphate, and sodium phosphate) to ultrafiltration retentate, reporting improved rehydration properties of resultant MPC powder. However, use of such additives generally impairs the processing characteristics (e.g., high viscosity), functionality (e.g., reduced casein micelle integrity) [14,15], or nutritional significance of protein enrichment.

Glycomacropeptide (GMP), a fraction of $k$-casein with 64 amino acids, is a bioactive peptide rich in branched-chain amino acids (e.g., isoleucine and valine) and free of aromatic amino acids (tryptophan, tyrosine, and phenylalanine), often used for the management of rare health conditions when phenylalanine metabolism is hindered (e.g., phenylketonuria) [16] and shows benefits for functional food applications [17]. GMP is generally glycosylated with sialic acid (N-acetyl neuraminic acid, NANA), rendering the peptide highly hydrophilic [18]. The peptide has one positively charged end, a middle segment (AA, 1-5, 17-22, 35-39, 58-65) containing mainly hydrophobic residues, and the other end bearing a negative charge due to glycosylation with sialic acid [19]. Some examples of the implications of this unique structure are that it tends to form a complex with gelatin through hydrophobic interactions [20] and protects against extensive aggregation between unfolded $\beta$-lactoglobulin at $\mathrm{pH} 6.7$ [18]. Likewise, the formation of protein aggregates in solutions of sodium caseinate or denatured $\beta$-lactoglobulin was reported to be suppressed by the presence of GMP $[18,21,22]$, providing evidence of electrostatic repulsion induced by GMP for preventing protein-protein interactions. GMP shows the tendency to self-associate at neutral $\mathrm{pH}$ in pure water in the presence of calcium $(>1.2 \mathrm{mmol} / \mathrm{g} \mathrm{GMP})$ through hydrophobic interaction [23], as the negative charge of sialic acid is screened by ionic calcium $\left(\mathrm{Ca}^{2+}\right)$ at neutral $\mathrm{pH}$ [24]. Consequently, it is hypothesized that GMP would enhance dissolution properties of high-protein dairy powders due to its highly hydrophilic nature; more specifically, incorporation of GMP in MCC solution at neutral $\mathrm{pH}$ would modulate electrostatic interactions between casein micelles, with consequent improvement of rehydration properties of subsequent high protein, casein-dominant powders. This study aimed to investigate the physicochemical properties of mixed protein systems containing MCC and GMP, as well as the rehydration characteristics of powders prepared therefrom. The results of this study will contribute to improving our understanding of the rehydration properties of high-protein dairy powders.

\section{Materials and Methods}

\subsection{Materials}

Spray-dried MCC (MCC-SD) powder was acquired from Milei (MILEI GmbH, Leutkirch im Allgäu, Germany), and spray-dried GMP powder (GMP-SD, BiPRO ${ }^{\circledR}$ GMP 9000) was acquired from Agropur (Agropur Ingredients, Suite 250A, Eden Prairie, MN, USA). MCCSD powder had a protein content of $88 \%$ ( $w / w$, dry basis) with casein $\geq 92 \%$, with reversedphase liquid chromatography analysis showing the presence of only casein fractions, while the protein content of the GMP-SD powder sample was $85 \%$ (w/w, dry basis), with no other casein factions detected using chromatographic analysis.

\subsection{Preparation of Micellar Casein Concentrate and Glycomacropeptide Solutions and Powders}

MCC solutions ( $8.6 \%$ protein) were prepared by dissolving MCC-SD powder in ultrapure water $(900 \mathrm{~g})$ at $45{ }^{\circ} \mathrm{C}$ using a high shear mixture (L4-RT Laboratory Mixer, Silverson, East Longmeadow, MA, USA) at $5100 \mathrm{rpm}$ for at least $30 \mathrm{~min}$ followed by stirring for $3 \mathrm{~h}$ using a magnetic stirrer at room temperature and overnight stirring at $4{ }^{\circ} \mathrm{C}$. GMP solutions were prepared by solubilizing GMP-SD powder $(12 \mathrm{~g})$ in $100 \mathrm{~g}$ ultrapure water to yield $8.6 \%$ protein, and the solutions were magnetically stirred for $4 \mathrm{~h}$ at room 
temperature, followed by overnight stirring at $4{ }^{\circ} \mathrm{C}$. This wet blending allowed for the replacement of 10 and $20 \%$ of total protein with GMP while maintaining total protein content constant. Experiments were designed at 0, 10, and 20\% GMP addition to achieve minimal changes in casein micelle size while altering the zeta potential on the basis of data obtained from preliminary trials. After blending MCC and GMP, the $\mathrm{pH}$ of all solutions was adjusted to 6.9 using $1 \mathrm{~N} \mathrm{NaOH} / \mathrm{HCl}$, after which the samples were stored overnight at $4{ }^{\circ} \mathrm{C}$ with magnetic stirring. Further $\mathrm{pH}$ adjustment to the samples was performed on the following day, if necessary. The prepared solutions for 0, 10, and 20\% GMP protein content were identified as S-MCC-0G, S-MCC-10G, and S-MCC-20G, respectively.

The powder samples were prepared from the MCC solutions with 0, 10, and $20 \%$ of GMP protein content (P-MCC-0G, P-MCC-10G, and P-MCC-20G) using the freezedrying technique. The obtained freeze-dried solids were converted into uniform powders using an ultracentrifugal mill operated at $6000 \mathrm{rpm}$ with an $80 \mu \mathrm{m}$ sieve (ZM 200, Retsch Centrifugal Mill, Carl Stuart Ltd., Dublin, Ireland) and stored in air-tight plastic bags at $4{ }^{\circ} \mathrm{C}$ until analyzed.

\subsection{Compositional Analysis of Protein Solutions and Powders}

The total nitrogen content of solutions and the respective powders was determined using Kjeldahl method [25]. The nitrogen to protein conversion factors used for MCC and GMP were 6.38 and 7.07, respectively [23]. The total solids content of solutions and powder samples were determined using oven drying $\left(103.5^{\circ} \mathrm{C}\right.$ for $\left.5 \mathrm{~h}\right)$ [26]. Powders were dry-ashed in a muffle furnace at $800^{\circ} \mathrm{C}$ for ash content determination.

\subsection{Particle Size and Charge in Protein Solutions}

Particle size of, and charge on, casein micelles in all prepared solutions were determined using a Zetasizer Nano series HT instrument (Malvern Instruments Ltd., Worcestershire, UK). For size measurement, refractive indices for protein and dispersant (i.e., water) were set at 1.46 and 1.33 , respectively. The dynamic light-scattering system utilized emission of He-Ne laser at $633 \mathrm{~nm}$ at the back-scattering configuration with a scattering angle of $173^{\circ}$. Samples were measured in triplicate at $25^{\circ} \mathrm{C}$ after $120 \mathrm{~s}$ of temperature equilibration.

\subsection{Morphology of Powders}

For morphological characterization, powder samples were attached to sticky rubber on an aluminum stub, which was then coated with gold and palladium ( $\mathrm{Au} / \mathrm{Pd})$ up to $5 \mathrm{~nm}$ thickness. Images of the powder samples were taken at magnifications of $70 \times$ and $420 \times$ using a scanning electron microscope (Jeol JSM-5510, Jeol Ltd., Tokyo, Japan) operated at $5 \mathrm{kV}$.

\subsection{Rehydration Properties of Powders}

\subsubsection{Contact Angle of Powder Samples}

Wettability of powder samples was measured using an optical tensiometer by determining the contact angle $(\theta)$ formed by a water droplet on the surface of powder tablets (Attension Theta, Biolin Scientific Ltd., Espoo, Finland). Briefly, the tablets were formed with a load of $5000 \mathrm{~kg}$ in a hydraulic press (Perkin Elmer, Buckinghamshire, UK) and the contact angle measurement was performed at $20^{\circ} \mathrm{C}$ over $52 \mathrm{~s}$ recording the images of a water droplet $(10 \mu \mathrm{L})$ spreading on the surface of the powder. The values of contact angle in the right-hand and left-hand sides were averaged during each measurement. Sample analyses were performed in triplicate on each freeze-dried powder, which was then averaged to represent the data from one sample. The contact angle data analysis for MCC powders was performed in triplicate independent trials $(n=3)$, while for the MCC-SD and GMP-SD samples, a total of four different samples were prepared and analyzed $(n=4)$ as analytical replicates. Contact angle data are expressed as an average of seven data points. 


\subsubsection{Dispersion Characteristics of Powders}

The dispersion characteristics of the powder samples were assessed optically using a Malvern Mastersizer 3000 (Malvern Instruments Ltd., Malvern, UK). Powder samples $(2.5 \mathrm{~g})$ were stirred in ultrapure water $(200 \mathrm{~mL})$ at $25^{\circ} \mathrm{C}$ and $500 \mathrm{rpm}$ for $240 \mathrm{~min}$. Aliquots of samples were transferred into the dispensing unit of the instrument at 1, 15, 30, 45, 60, 90, 180, and $240 \mathrm{~min}$. The instrument conditions selected were stirrer speed $1290 \mathrm{rpm}$, laser obscuration of $13 \pm 2 \%$ with ultrapure water as dispersant. Analysis of PSD was performed using the spherical model, with particle refractive index of 1.46, absorption of 0.001 , and dispersant refractive index of $1.33[27,28]$. The area under the curves for volume-based-PSD data for each primary powder peak $(>1 \mu \mathrm{m})$ and casein micelles peak $(<1 \mu \mathrm{m})$ were integrated with the trapezoidal rule approach using Microsoft Excel and plotted against rehydration time.

\subsection{Protein Release in Solution during Powder Rehydration}

Release of caseins $(\alpha-, \beta-, k$-casein) and GMP from primary powder particles as a function of rehydration time was assessed by measuring the protein content in supernatant obtained after centrifugation. Powder $(650 \mathrm{mg})$ was dissolved in ultrapure water $(50 \mathrm{~mL})$ at $25^{\circ} \mathrm{C}$ using a magnetic stirrer at $300 \mathrm{rpm}$. Aliquots $(2 \mathrm{~mL})$ of the dispersions were removed at 15,45 , and $90 \mathrm{~min}$ and $24 \mathrm{~h}$ and centrifuged at $700 \times \mathrm{g}$ at $20^{\circ} \mathrm{C}$ for $10 \mathrm{~min}$, after which the supernatant was separated from the sediment and frozen. After thawing, the supernatant was mixed 1:1 with sample buffer and filtered using $0.20 \mu$ m nylon filters before injection on $\mathrm{a} \mathrm{C}_{18}$ column $(3.6 \mu \mathrm{m} \times 250 \mathrm{~mm} \times 4.6 \mathrm{~mm}$, Aeris Widepore, Phenomenex, Cheshire, UK) for reversed-phase high-performance liquid chromatography (RP-HPLC; Agilent 1220 Infinity II LC, Santa Clara, CA, USA). The composition of sample buffer and the gradient for mobile phase solvents required for generating chromatograms were as described previously [29]. Peak areas of individual milk proteins were integrated, and the data were converted to relative percentage on the basis of the area of samples measured after $24 \mathrm{~h}$ of rehydration. Powder rehydration was considered to be complete at $24 \mathrm{~h}$, on the basis that P-MCC-0G and P-MCC-20G displayed similar particle size values after $240 \mathrm{~min}$ of rehydration.

\subsection{Data Analysis}

Normality and homogeneity test of variance was checked, and data were analyzed using one-way ANOVA with a Tukey test for multiple comparisons between treatments at 95\% confidence level using SPSS (IBM SPSS Statistics for Windows, version 24, IBM Corp, Arnomk, NY, USA).

\section{Results and Discussion}

\subsection{Physicochemical Properties of Protein Solutions}

The physicochemical properties of MCC and GMP blended solutions are shown in Table 1. The prepared MCC solutions (S-MCC-0G, S-MCC-10G, and S-MCC-20G) had similar levels of total solids, protein, and protein on a dry basis, with values in the ranges of $9.77-9.92 \%, 8.64-8.58 \%$, and $88.5-86.6 \%$, respectively. The surface charge (zeta potential) of casein micelles in S-MCC-0G was $-25.82 \mathrm{mV}$. With the inclusion of GMP in MCC at 10 or $20 \%$ of total protein in MCC solution, the negative surface charges increased to -29.6 and $-32.6 \mathrm{mV}$, respectively. The more negative surface charge of the MCC-GMP blends was attributed to acidic amino acid residues and glycosylation of GMP [21], rendering the peptide highly hydrophilic; indeed, the zeta potential of $1 \%$ GMP solution at $\mathrm{pH} 6.5$ has been reported to be $-24.12 \mathrm{mV}$ [20]. The distribution of casein micelle size in the S-MCC0G, S-MCC-10G, and S-MCC-20G was similar (Figure S1), suggesting that casein micelle size and integrity was not influenced by higher levels of GMP in the MCC solutions. 
Table 1. Composition and physicochemical properties of MCC solutions mixed with 0 (S-MCC-0G), 10 (S-MCC-10G), and 20 (S-MCC-20G) \% GMP as a percentage of total protein.

\begin{tabular}{cccc}
\hline Parameter & S-MCC-0G & S-MCC-10G & S-MCC-20G \\
\hline Total solids $(\%, w / w)$ & $9.77 \pm 0.11^{\mathrm{a}}$ & $9.90 \pm 0.13^{\mathrm{a}}$ & $9.92 \pm 0.14^{\mathrm{a}}$ \\
Protein $(\%, w / w)$ & $8.64 \pm 0.08^{\mathrm{a}}$ & $8.58 \pm 0.09^{\mathrm{a}}$ & $8.59 \pm 0.18^{\mathrm{a}}$ \\
Protein $(\%, w / w$, dry basis) & $88.5 \pm 0.72^{\mathrm{a}}$ & $86.7 \pm 0.31^{\mathrm{a}}$ & $86.6 \pm 1.21^{\mathrm{a}}$ \\
Zeta potential $(\mathrm{mV})$ & $-25.8 \pm 1.37^{\mathrm{b}}$ & $-29.6 \pm 1.97^{\mathrm{ab}}$ & $-31.6 \pm 1.09^{\mathrm{a}}$ \\
\hline
\end{tabular}

The values are mean \pm standard deviation $(n=3)$. ${ }^{\mathrm{b}}$ superscript letters, within a row, indicate statistically significant differences at a $95 \%$ confidence level.

\subsection{Composition and Microstructure of Protein Powders}

The moisture and protein contents of P-MCC-0G, P-MCC-10G, and P-MCC-20G were similar $(p>0.05)$, with moisture values of $4.0,3.5$, and $4.4 \%(w / w)$ and protein contents ( $w / w$, dry basis) of $88.5,85.8$, and $83.8 \%$, respectively. The ash contents $(w / w$, dry basis) of P-MCC-0G, P-MCC-10G, P-MCC-20G were 8.04 $\pm 0.04,7.85 \pm 0.09$, and $7.54 \pm 0.02 \%$, respectively. The decrease in ash content with increasing proportion of GMP was partly due to lower ash content in GMP-SD (5.75\%, w/w, dry basis) compared to MCC. The morphology of all powders appeared highly angular, with broken pieces evident at $70 \times$ magnification, and attachment of fine particles on the surface in those powders was revealed at magnification $430 \times$ (Figure 1). As expected, powder morphological characteristics were similar between samples regardless of GMP content, and this was attributed to the use of ultracentrifugal milling prior to analysis [29]. However, it is important to note that the morphological characteristics of freeze-dried powders differ greatly from powders produced using spray-drying, in terms of interstitial and occluded air contents and surface properties [8]. Freeze-drying was intentionally chosen in this study, as the advantage of structural uniformity in freeze-dried powders enables more accurate and direct study of the linkages between composition and rehydration properties of powders by minimizing the influence of differences in structural characteristics of powders.
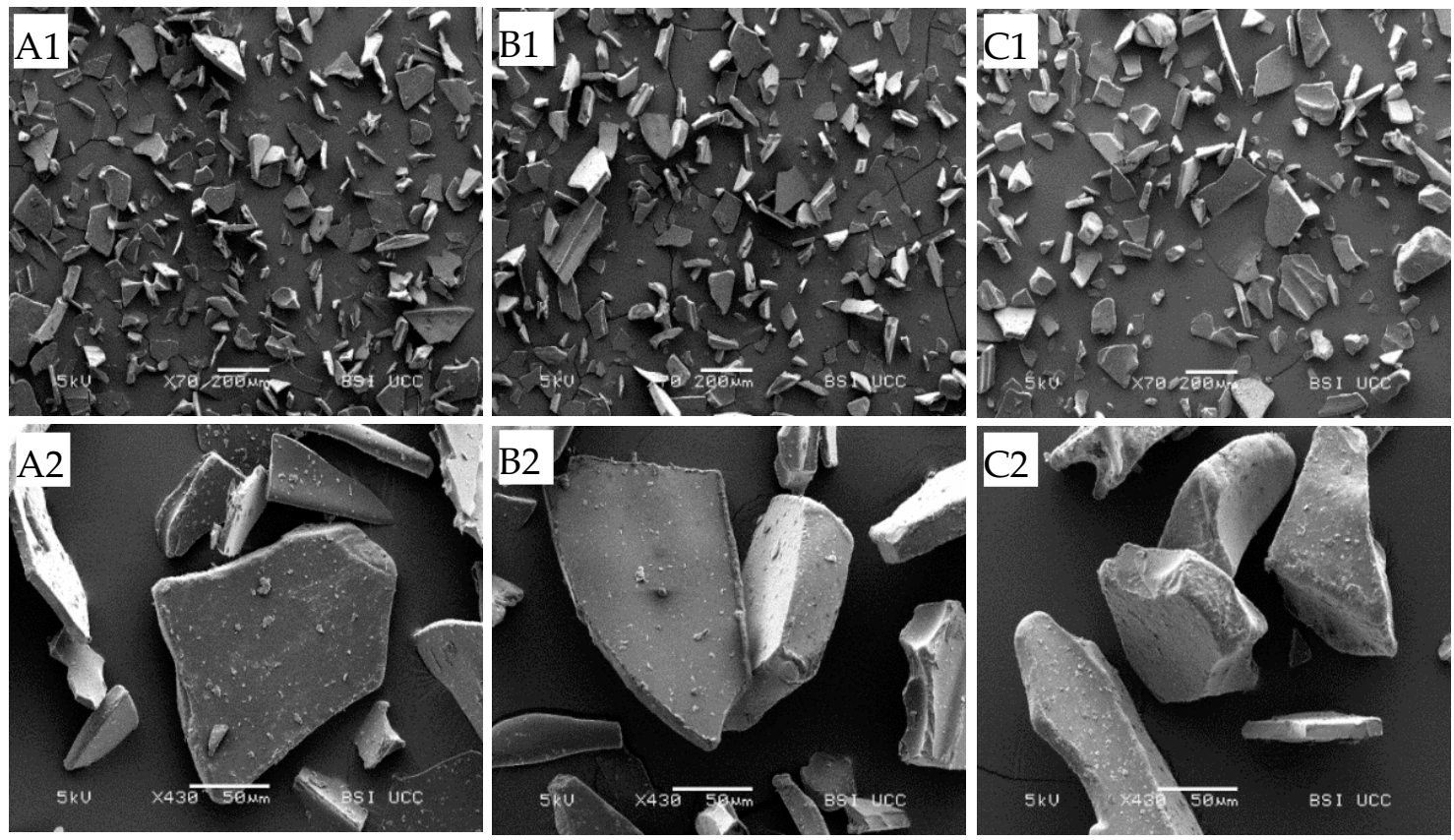

Figure 1. Scanning electron microscopy images (A1-C1, 70×, and A2-C2, 430 $\times$ ) of freeze-dried MCC powder: (A) (P-MCC0G), (B) (P-MCC-10G), and (C) (P-MCC-20G) prepared from MCC solutions containing 0, 10, and 20\% GMP as a percentage of total protein, respectively. 


\subsection{Wettability of Micellar Casein Concentrate Powders}

Wettability of the powder samples, expressed as contact angle ( $\theta)$, P-MCC-0G, PMCC-10G, and P-MCC-20G, including the original MCC-SD and GMP-SD powders, is given in Figure 2. The contact angle data of MCC-SD and GMP-SD provide the basis for comparison between all freeze-dried MCC powders produced in this study. As expected, the MCC-SD powder had the highest $\theta$ value $\left(86.9^{\circ}\right)$ initially, decreasing slightly to $85.6^{\circ}$, demonstrating that the original spray-dried powder had poor wettability in water. The observed $\theta$ values were close to those for other high-protein dairy powders, such as MPC, which displayed $\theta$ values of $\approx 75^{\circ}$ [28]. On the other hand, GMP-SD powder exhibited the lowest $\theta$ values $\left(40.5^{\circ}\right)$, ultimately reaching $31.5^{\circ}$. As GMP is highly hydrophilic, tablets prepared from GMP-SD powder interacted rapidly with water and allowed the spreading of water droplets (Figure S2). Sample P-MCC-0G, which is the freeze-dried powder of MCC solution without GMP, had a $\theta$ value $85.5^{\circ}$ initially, which is close to that displayed by the original MCC-SD, and decreased to $80^{\circ}$, indicating that freeze-dried powder interacted more quickly with water compared to spray-dried original MCC-SD powder. On inclusion of 10 or $20 \%$ GMP of total protein in the samples P-MCC-10G or P-MCC-20G, the initial $\theta$ values of $80.6^{\circ}$ and $79.5^{\circ}$ decreased to $75.7^{\circ}$ and $75.2^{\circ}$, respectively, being lower than that observed for P-MCC-0G. These results demonstrated that the wettability of powders was enhanced with the addition of GMP. Overall, results derived from the wettability analysis indicated that the power samples prepared with the addition of GMP prior to drying had enhanced capability to interact with water compared to powder prepared without GMP addition or the original MCC-SD powder.

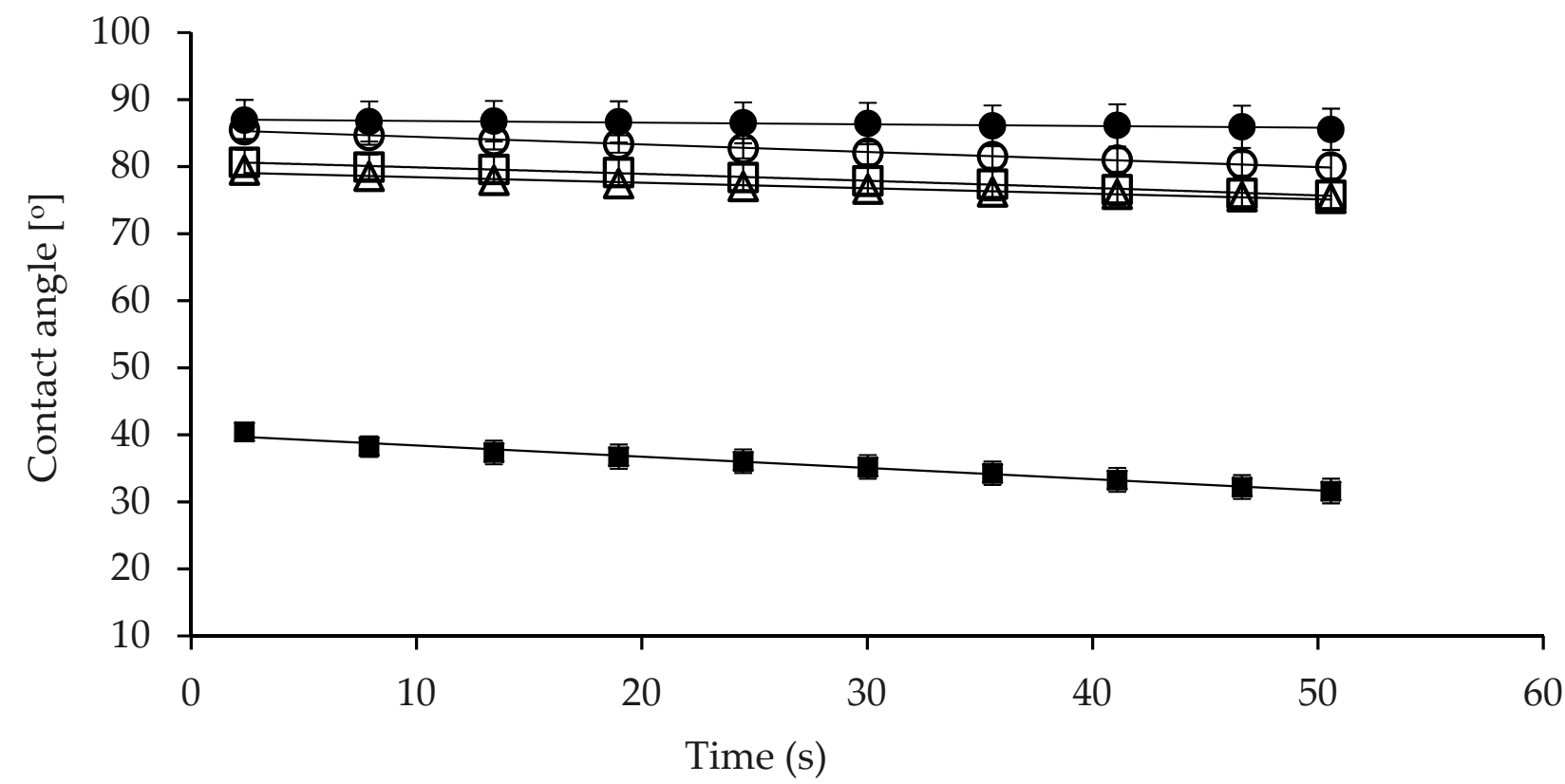

Figure 2. Contact angle values of water droplets on the surface of powder tablets from: • MCC-SD, spray-dried original powder; $\bigcirc$ P-MCC-0G, freeze-dried MCC powder without GMP addition; $\square$ P-MCC-10G, freeze-dried MCC prepared with $10 \%$ GMP as a percentage of total protein; $\triangle$ P-MCC-20G, freeze-dried MCC prepared with $20 \%$ GMP as a percentage of total protein; GMP-SD, original spray-dried GMP powder, as a function of time. The error bars represent standard error.

\subsection{Kinetics of Powder Dispersion}

The particle size distribution (PSD) of the powder samples was measured over $240 \mathrm{~min}$ of dynamic rehydration analysis. The particle size measured at $1 \mathrm{~min}$ after rehydration closely represents the average particle size of powders prior to rehydration. The volumeweighted mean particle size $\left(\mathrm{D}_{4,3}\right)$ of powders P-MCC-0G, P-MCC-10G, and P-MCC-20G measured at $1 \mathrm{~min}$ of rehydration was in the range 132-156 $\mu \mathrm{m}$, which is close to the size $(120 \mu \mathrm{m})$ of MCC-SD original powder (Figure S3). The data for the PSD of GMP-SD powder 
could not be generated in this study as powders disintegrated rapidly in water. The value of $\mathrm{D}_{4,3}$ remained relatively constant for MCC-SD, whereas, for P-MCC-0G, P-MCC-10G, and P-MCC-20G, $\mathrm{D}_{4,3}$ decreased with increasing rehydration time up to $240 \mathrm{~min}$ (Figure S3). The decrease in particle size was due to disintegration of larger powder particles, with concomitant release of smaller particles [4], which is evident from the initial decrease in the size/volume of the peak of size range $1-1000 \mu \mathrm{m}$ and the appearance of a peak in the size range $0.01-1 \mu \mathrm{m}$ over time (Figure S4). To assess the kinetics of primary particle dispersion, we integrated the area under the curve of volume density as a function of particle size for primary powder particles and casein micelles separately and plotted as a function of rehydration time (Figure 3). The integrated area of primary powder particles decreased rapidly for P-MCC-10G and P-MCC-20G compared to P-MCC-0G, suggesting that the volume density of primary powder particles decreased due to particle disintegration as the rehydration progressed. Increasing the proportion of GMP in the powders resulted in a higher rate of particle disintegration (Figure 3A), with a concomitant increase in the area of casein micelles peak observed during rehydration (Figure 3B). The trend of increasing area across all powders progressed from an initial constant phase, through a rapid increase phase, and on to a plateau phase. P-MCC-20G had the shortest initial constant phase and a steeper/faster increase phase compared to P-MCC-10G, suggesting that a greater proportion of GMP in the former facilitated faster and more extensive disruption of larger powder particles into casein micelles. Although P-MCC-0G showed a decrease in particle size up to $90 \mathrm{~min}$, the appearance of a peak related to casein micelles was not observed using this analytical method. This could be due to the volume density of primary powder particles being significantly higher for targeted obscuration during measurement, in which the volume fraction of casein micelles could be negligible. It is apparent that by the time the casein micelles area of P-MCC-20G reached the plateau phase, P-MCC-0G was at the initial constant phase. This suggests that there was a significant improvement in the dispersibility of powder particles prepared with GMP addition. While the focus of the study was not on comparing the data between original MCC-SD and freeze-dried powders, these results provided further evidence that freeze-dried powder rehydrates more quickly and that incorporation of GMP in MCC solution further enhances particle disintegration compared to original MCC-SD powder.
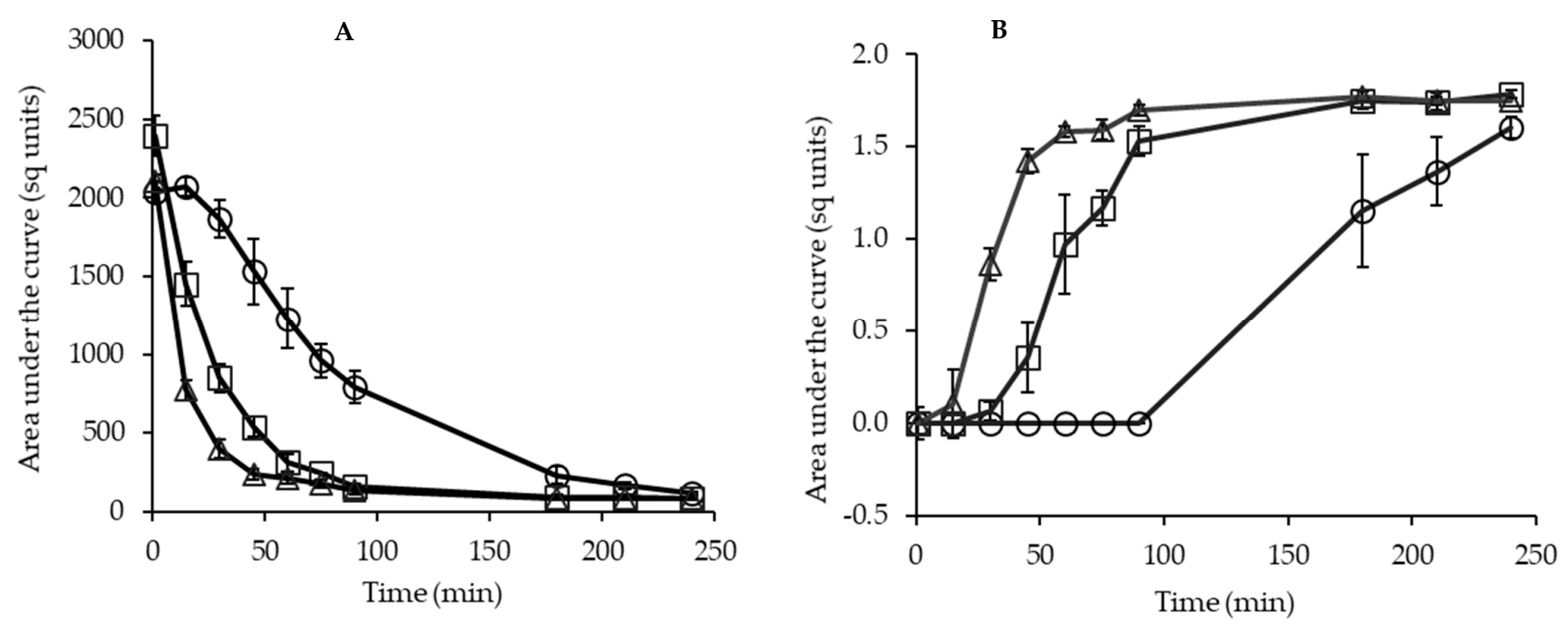

Figure 3. Distribution of area under the curve integrated from the peaks of volume density above $1 \mu \mathrm{m}(\mathbf{A})$ and below $1 \mu \mathrm{m}$ (B) during rehydration of powders: $\bigcirc$ P-MCC-0G, $\square$ P-MCC-10G, and $\triangle$ P-MCC-20G mixed with 0, 10, and 20\% GMP as a percentage of total protein, respectively. The error bars show the standard error.

Various techniques have been previously explored for improving the dispersion characteristics of casein-rich powders. For example, dispersant with higher ionic strength $(\mathrm{KCl}$, $80 \mathrm{mM})$, temperature $\left(25-50^{\circ} \mathrm{C}\right)$ and ultrafiltration milk permeate [28], calcium-binding 
agents (e.g., trisodium citrate or sodium hexametaphosphate) [14], or pH-mediated changes (up to $\mathrm{pH}$ 8.4) [30] have been shown to improve the dissolution of poorly soluble spraydried MPC and milk protein isolate powders. On the other hand, emerging technologies such as hydrodynamic cavitation [31], ultrasonication [32], the use of $\mathrm{CO}_{2}$ to porosify MPC concentrate prior to drying [33], and high pressure (100 to $400 \mathrm{MPa}$ ) treatment of MPC solutions [34] have been explored for enhancing rehydration. However, such mechanical processes are energy-intensive and require an adjustment in process lines, adding capital expenditure and processing complexity [3]. Although alteration of chemical interactions between caseins by chelating calcium using sodium hexametaphosphate and maintaining casein integrity by treatment with polygalacturonase enzyme [15], pH adjustment to an alkaline range [29], or by dry blending MPI powder with sodium caseinate [35] show promising results for enhanced rehydration, these techniques involve chemical addition or generate non-micellar caseins that are normally undesirable for many applications. The results from the present study show the potential that formulation of MCC solutions with GMP enhances powder particle disintegration during rehydration through the use of dairy-based food ingredients with potential benefits from a nutritional perspective.

\subsection{Casein and Glycomacropeptide Solubilization in Aqueous Phase during Powder Dispersion}

The relative release of proteins from powder particles into the dispersant solution at 15,45 , and $90 \mathrm{~min}$, based on analysis of protein concentration in samples withdrawn after $24 \mathrm{~h}$, is shown in Figure 4. In P-MCC-0G, protein solubility in terms of $\mathrm{K}_{-}, \alpha_{-}^{-}$, and $\beta$-casein ranged between 11 and $34 \%, 2$ and $16 \%$, and 11 and $30 \%$, respectively, during rehydration over $90 \mathrm{~min}$. Both P-MCC-10G and P-MCC-20G, at 15, 45, and $90 \mathrm{~min}$, had protein solubility values greater than P-MCC-0G. For P-MCC-10G, 83 to 81\% GMP, 18 to 69\% K-casein, 4 to $65 \% \alpha$-casein, and 14 to $68 \% \beta$-casein were detected in the same rehydration time. Similarly, for P-MCC-20G, 98 to $86 \%$ of GMP, 29 to $90 \%$ K-casein, 13 to $90 \% \alpha$-casein, and 19 to $86 \%$ $\beta$-casein were identified. While caseins were diffusing slowly and progressively during rehydration, at 15 min of rehydration, both blended samples had more than $80 \%$ of GMP in the soluble form. The diffusion of GMP from powder particles into dispersant in the present study was independent of casein solubility, a trend which is similar to that observed with whey proteins diffusivity as analyzed in spray-dried MPC powders [10,36,37]. Faster dispersibility of P-MCC-10G or P-MCC-20G, compared to that of P-MCC-0G, supports the fact that development of insolubility in casein-dominant powder is principally due to the interactions of caseins within powder particles.

The extensive solubilization of GMP within the first 15 min of rehydration further supports the fact that the mobility of GMP within casein-dominant powder particles was not restricted, displaying characteristics similar to fast diffusing components, e.g., whey proteins and minerals [36]. Farias et al. [19] reported hydrodynamic diameter of GMP in the range 1 to $5 \mathrm{~nm}$, with an average size being $2.5 \mathrm{~nm}$ at $\mathrm{pH}$ 6.7. Increase in aggregate size due to self-association of GMP molecules in MCC solution is less likely to occur towards neutral $\mathrm{pH}$ as GMP molecules acquire negative charge from Asp, Glu, and sialic acid, with net electrostatic repulsion, while the probability of hydrophobic interaction at domains AA1-5, 17-22, 35-39, and 58-65 would also be minimal [19]. Therefore, GMP in MCC solution is likely to be retained at the interface between caseins in their monomeric state, both in solution and powder form, exhibiting electrostatic repulsion between casein micelles. The lower negative values of zeta potential in the MCC solution blended with GMP (Table 1) further supports the fact that interparticle repulsion was greater in MCC-GMP powder blends. The rapid disintegration of P-MCC-10G and P-MCC-20G powders into caseins supports the hypothesis that GMP played the role in restricting interaction of caseins, as the ingress of water into powder particles was not determined to be a major factor contributing to powder disintegration, as shown by particles larger than water molecules being released shortly after rehydration $[10,37]$. 

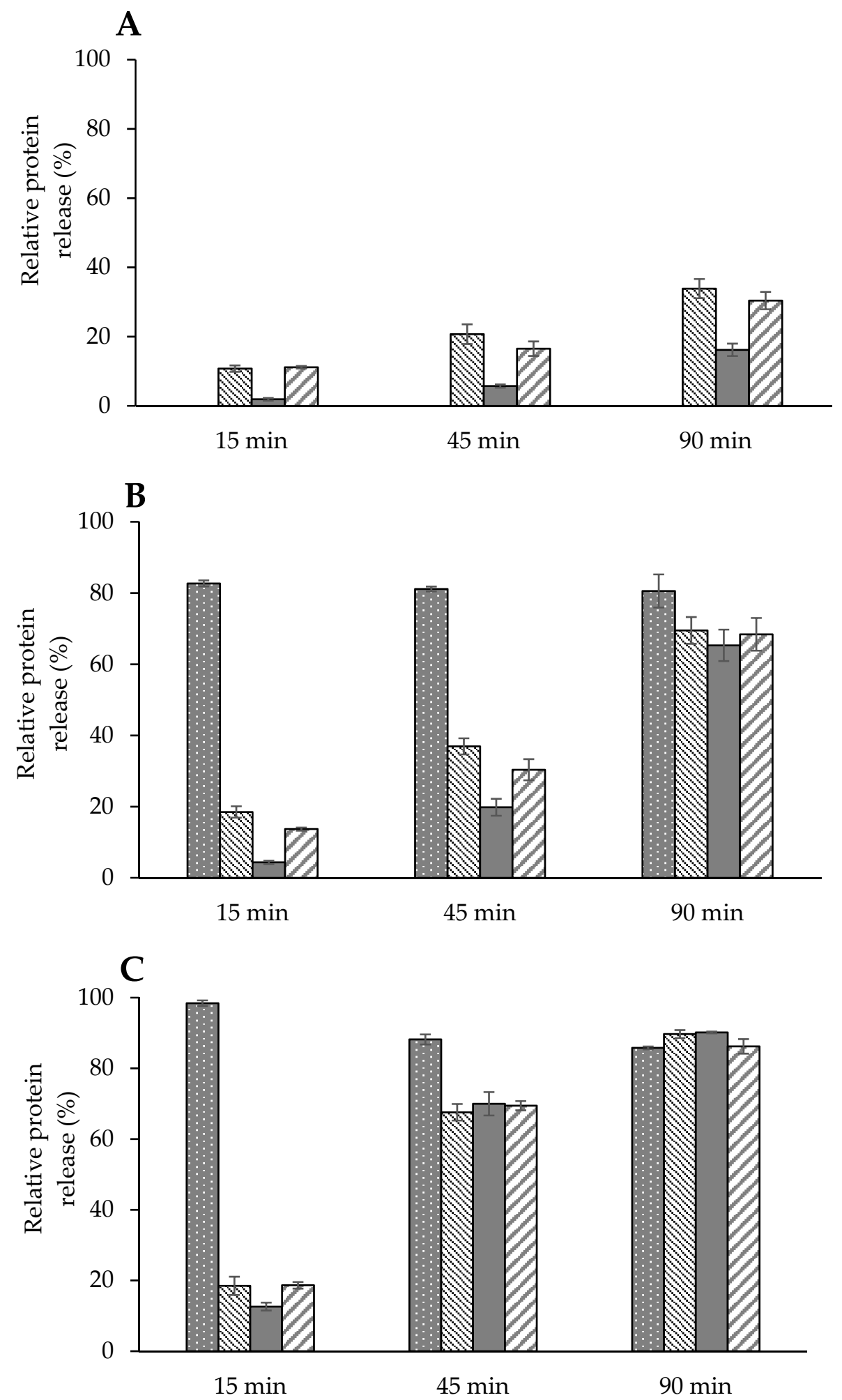

Figure 4. Relative release of proteins GMP $(\square), k(\mathbb{\mathbb { Q }}), \alpha(\square)$, and $\beta(\square)$ caseins in solution at $25^{\circ} \mathrm{C}$ as a function of rehydration time. (A) Dispersion of powder containing no GMP (P-MCC-0G), (B) dispersion of powder containing 10\% GMP (P-MCC-10G), or (C) 20\% GMP (P-MCC-20G) as a percentage of total protein.

\section{Conclusions}

This study investigated the influence of GMP on physicochemical properties of proteins in mixed MCC and GMP solutions and the rehydration characteristics of subsequent 
freeze-dried powders. Partial replacement of MCC with 10 or $20 \%$ GMP resulted in blended protein solutions with lower zeta potential, without influencing casein micelle size. The subsequent powders had enhanced wettability when compared to powders without inclusion of GMP. Blending of MCC with GMP to $20 \%$ of total protein resulted in rapid and extensive disintegration of primary powder particles, with faster and more extensive release of casein into solution. The current study demonstrated that the interactions between casein micelles can be modulated by GMP for improved rehydration characteristics of high-protein dairy powders, such as MCC. The results of this study provide novel insights in developing next-generation high-protein dairy powders with nutri-functional benefits associated with the added GMP.

Supplementary Materials: The following are available online at https://www.mdpi.com/article/ 10.3390/foods10081960/s1, Figure S1: Distribution of casein micelle size in mixed micellar casein concentrate (MCC) and glycomacropeptide (GMP) protein solutions: $\bigcirc$ S-MCC-0G, $\square$ S-MCC-10G, and $\triangle$ S-MCC-20G mixed with 0,10 , and $20 \%$ GMP as a percentage of total protein, respectively. Figure S2: Representative images of water droplet on the surface of powder tablets: MCC-SD (spraydried original powder), P-MCC-0G (freeze-dried MCC powder without GMP addition), P-MCC-10G (freeze-dried MCC prepared with 10\% GMP as a percentage of total protein), P-MCC-20G (freezedried MCC prepared with $20 \% \mathrm{GMP}$ as a percentage of total protein), GMP-SD (original spray-dried GMP powder) at $50 \mathrm{~S}$. Figure S3: Volume-weighted mean particle size $\left(\mathrm{D}_{4,3}\right)$ of micellar casein powders: $\bigcirc$ P-MCC-0G, $\square$ P-MCC-10G, and $\triangle$ P-MCC-20G obtained from micellar casein concentrate mixed with GMP prior to drying including original spray-dried MCC powder $(\bullet$ MCC-SD). The mean particle size values are shown as a function of rehydration time from 1 to $240 \mathrm{~min}$ and error bars represent standard error. Figure S4. Particle size distribution data of micellar casein powders: $\bigcirc$ P-MCC-0G, $\square$ P-MCC-10G, and $\triangle$ P-MCC-20G obtained from micellar casein mixed with GMP at 0,10 , and $20 \%$ of total protein prior to drying. The PSD data are shown as a function of rehydration time: A (1 min), B (15 min), C (30 min), D (45 min), E (60 min), F (90 min), G (180 min), H (210 min), and I (240 min).

Author Contributions: Conceptualization, R.R.P. and J.A.O.; methodology, R.R.P.; analysis, R.R.P. and F.B.; data curation, R.R.P.; writing—original draft preparation, R.R.P.; writing—review and editing, R.R.P., F.B. and J.A.O.; supervision, J.A.O.; funding acquisition, J.A.O. All authors have read and agreed to the published version of the manuscript.

Funding: This research was funded by the Irish Department of Agriculture, Food and the Marine and supported by the Food Institutional Research Measure (FIRM) for the project "Developing the next generation of high protein spray-dried dairy powders with enhanced hydration properties" (DAIRYDRY 15-F-679)".

Acknowledgments: The authors would like to acknowledge Jonas Joachim Atzler for operating the sputter coating instrument required for SEM images.

Conflicts of Interest: The authors declare no conflict of interest.

\section{References}

1. Agarwal, S.; Beausire, R.L.; Patel, S.; Patel, H. Innovative uses of milk protein concentrates in product development. J. Food Sci. 2015, 80 (Suppl. 1), A23-A29. [CrossRef]

2. Felix da Silva, D.; Ahrné, L.; Ipsen, R.; Hougaard, A.B. Casein-based powders: Characteristics and rehydration properties. Compr. Rev. Food Sci. Food Saf. 2018, 17, 240-254. [CrossRef]

3. Crowley, S.V.; Kelly, A.L.; Schuck, P.; Jeantet, R.; O'Mahony, J.A. Rehydration and solubility characteristics of high-protein dairy powders. In Advanced Dairy Chemistry; McSweeney, P.L.H., O'Mahony, J.A., Eds.; Springer: New York, NY, USA, 2016; pp. 99-131.

4. Mimouni, A.; Deeth, H.C.; Whittaker, A.K.; Gidley, M.J.; Bhandari, B.R. Rehydration process of milk protein concentrate powder monitored by static light scattering. Food Hydrocoll. 2009, 23, 1958-1965. [CrossRef]

5. Maidannyk, V.; Lutjes, E.; Montgomery, S.; McCarthy, N.; Auty, M.A.E. Measurement of effective diffusion coefficients in dairy powders by confocal microscopy and sorption kinetic profiles. Food Struct. 2019, 20, 100108. [CrossRef]

6. Schuck, P.; Mejean, S.; Dolivet, A.; Gaiani, C.; Banon, S.; Scher, J.; Jeantet, R. Water transfer during rehydration of micellar casein powders. Lait 2007, 87, 425-432. [CrossRef]

7. Mimouni, A.; Deeth, H.C.; Whittaker, A.K.; Gidley, M.J.; Bhandari, B.R. Investigation of the microstructure of milk protein concentrate powders during rehydration: Alterations during storage. J. Dairy Sci. 2010, 93, 463-472. [CrossRef] 
8. Fyfe, K.N.; Kravchuk, O.; Le, T.; Deeth, H.C.; Nguyen, A.V.; Bhandari, B.R. Storage induced changes to high protein powders: Influence on surface properties and solubility. J. Sci. Food Agric. 2011, 91, 2566-2575. [CrossRef]

9. Dalgleish, D.G.; Corredig, M. The structure of the casein micelle of milk and its changes during processing. Annu. Rev. Food Sci. Technol. 2012, 3, 449-467. [CrossRef]

10. Anema, S.G.; Pinder, D.N.; Hunter, R.J.; Hemar, Y. Effects of storage temperature on the solubility of milk protein concentrate (MPC85). Food Hydrocoll. 2006, 20, 386-393. [CrossRef]

11. Bansal, N.; Truong, T.; Bhandari, B. Feasibility study of lecithin nanovesicles as spacers to improve the solubility of milk protein concentrate powder during storage. Dairy Sci. Technol. 2017, 96, 861-872. [CrossRef]

12. Schokker, E.P.; Church, J.S.; Mata, J.P.; Gilbert, E.P.; Puvanenthiran, A.; Udabage, P. Reconstitution properties of micellar casein powder: Effects of composition and storage. Int. Dairy J. 2011, 21, 877-886. [CrossRef]

13. Sun, Y.; Liu, Z.; Li, H.; Li, S.; Mo, B.; Lv, J. Functionality of milk protein concentrate 80 with emulsifying salts and its applications in analogue cheeses. Int. J. Food Prop. 2016, 20, 2594-2607. [CrossRef]

14. McCarthy, N.A.; Power, O.; Wijayanti, H.B.; Kelly, P.M.; Mao, L.; Fenelon, M.A. Effects of calcium chelating agents on the solubility of milk protein concentrate. Int. J. Dairy Tech. 2017, 70, 415-423. [CrossRef]

15. Power, O.M.; Fenelon, M.A.; O'Mahony, J.A.; McCarthy, N.A. Influence of sodium hexametaphosphate addition on the functional properties of milk protein concentrate solutions containing transglutaminase cross-linked proteins. Int. Dairy J. 2020, $104,104641$. [CrossRef]

16. Sharma, R.; Rajput, Y.S.; Mann, B. Chemical and functional properties of glycomacropeptide (GMP) and its role in the detection of cheese whey adulteration in milk: A review. Dairy Sci. Technol. 2013, 93, 21-43. [CrossRef]

17. Manso, M.A.; Lopez-Fandio, R. к-Casein macropeptides from cheese whey: Physicochemical, biological, nutritional, and technological features for possible uses. Food Rev. Int. 2004, 20, 329-355. [CrossRef]

18. Croguennec, T.; Leng, N.; Hamon, P.; Rousseau, F.; Jeantet, R.; Bouhallab, S. Caseinomacropeptide modifies the heat-induced denaturation-aggregation process of $\beta$-lactoglobulin. Int. Dairy J. 2014, 36, 55-64. [CrossRef]

19. Farias, M.E.; Martinez, M.J.; Pilosof, A.M.R. Casein glycomacropeptide pH-dependent self-assembly and cold gelation. Int. Dairy J. 2010, 20, 79-88. [CrossRef]

20. Martinez, M.J.; Pizones Ruiz-Henestrosa, V.M.; Carrera Sanchez, C.; Rodriguez Patino, J.M.; Pilosof, A.M.R. Foaming and surface properties of casein glycomacropeptide-gelatin mixtures as affected by their interactions in the aqueous phase. Food Hydrocoll. 2013, 33, 48-57. [CrossRef]

21. Morales, R.; Martinez, M.J.; Pilosof, A.M.R. Synergistic effect of casein glycomacropeptide on sodium caseinate foaming properties. Colloids Surf. B. 2017, 159, 501-508. [CrossRef] [PubMed]

22. Morales, R.; Martinez, M.J.; Pilosof, A.M.R. Impact of casein glycomacropeptide on sodium caseinate self-assembly and gelation. Int. Dairy J. 2015, 49, 30-36. [CrossRef]

23. Loria, K.G.; Pilosof, A.M.R.; Farías, M.E. Influence of calcium and sodium chloride on caseinomacropeptide self-assembly and flow behaviour at neutral pH. LWT 2018, 98, 598-605. [CrossRef]

24. Jaques, L.W.; Brown, E.B.; Barrett, J.M.; Brey, W.S.; Weltner, W. Sialic-acid-A calcium-binding carbohydrate. J. Biol. Chem. 1977, 252, 4533-4538. [CrossRef]

25. ISO. Milk-Determination of Nitrogen Content; ISO 8969-2. IDF Standard 20-2; International Dairy Federation: Brussels, Belgium, 2001.

26. IDF. Dried Milk and Dried Cream—Determination of Water Content; Standard No. 5537; International Dairy Federation: Brussels, Belgium, 1993.

27. Poste, G.; Moss, C. The study of surface reactions in biological systems by ellipsometry. Prog. Surf. Sci. 1972, 2, 139-232. [CrossRef]

28. Crowley, S.V.; Desautel, B.; Gazi, I.; Kelly, A.L.; Huppertz, T.; O'Mahony, J.A. Rehydration characteristics of milk protein concentrate powders. J. Food Eng. 2015, 149, 105-113. [CrossRef]

29. Panthi, R.R.; Bot, F.; Shibu, S.N.; Saladukha, D.; Ochalski, T.J.; O'Mahony, J.A. Influence of pH adjustment on physicochemical properties of microfiltration retentates of skim milk and rehydration properties of resulting powders. Int. Dairy J. $2021,116$. [CrossRef]

30. Wu, S.; Fitzpatrick, J.; Cronin, K.; Miao, S. The effect of pH on the wetting and dissolution of milk protein isolate powder. J. Food Eng. 2019, 240, 114-119. [CrossRef]

31. Pathania, S.; Ho, Q.T.; Hogan, S.A.; McCarthy, N.; Tobin, J.T. Applications of hydrodynamic cavitation for instant rehydration of high protein milk powders. J. Food Eng. 2018, 225, 18-25. [CrossRef]

32. McCarthy, N.A.; Kelly, P.M.; Maher, P.G.; Fenelon, M.A. Dissolution of milk protein concentrate (MPC) powders by ultrasonication. J. Food Eng. 2014, 126, 142-148. [CrossRef]

33. Bouvier, J.-M.; Collado, M.; Gardiner, D.; Scott, M.; Schuck, P. Physical and rehydration properties of milk protein concentrates: Comparison of spray-dried and extrusion-porosified powders. Dairy Sci. Technol. 2013, 93, 387-399. [CrossRef]

34. Udabage, P.; Puvanenthiran, A.; Yoo, J.A.; Versteeg, C.; Augustin, M.A. Modified water solubility of milk protein concentrate powders through the application of static high pressure treatment. J. Dairy Res. 2012, 79, 76-83. [CrossRef]

35. Bot, F.; Crowley, S.V.; O'Mahony, J.A. Solubility enhancement of milk protein isolate by sodium caseinate addition: Comparison between wet- and dry-blending approaches. Int. Dairy J. 2020, 105, 104661. [CrossRef] 
36. Mimouni, A.; Deeth, H.C.; Whittaker, A.K.; Gidley, M.J.; Bhandari, B.R. Rehydration of high-protein-containing dairy powder: Slow- and fast-dissolving components and storage effects. Dairy Sci. Tech. 2010, 90, 335-344. [CrossRef]

37. Gazi, I.; Huppertz, T. Influence of protein content and storage conditions on the solubility of caseins and whey proteins in milk protein concentrates. Int. Dairy J. 2015, 46, 22-30. [CrossRef] 